\title{
LOS ALCANCES DE LA AUTONOMÍA PRIVADA EN EL RÉGIMEN DE LA PRESCRIPCIÓN EXTINTIVA Y LA CADUCIDAD EN EL DERECHO CIVIL.
}

\author{
DR. JORGE RODRÍGUEZ RUSSO*
}

\section{RESUMEN}

El presente artículo tiene por objeto examinar los alcances de la autonomía privada en el régimen de la prescripción extintiva y la caducidad en el Derecho Civil, con especial referencia al Derecho uruguayo. El problema fundamental es que nuestro Código Civil regula de manera insuficiente la prescripción extintiva, no disciplina la caducidad de los derechos y tampoco contiene normas sobre el espacio que le cabe a la autonomía privada en el régimen de estas instituciones.

Los objetivos del trabajo son demostrar que a pesar de estas deficiencias en la regulación es posible reconocer de manera precisa un cierto margen para la voluntad de los particulares, en sintonía con las modernas legislaciones en el Derecho Comparado, a la vez que poner de relieve la necesidad de una profunda reforma de nuestro Código Civil.

El tratamiento del tema será realizado desde una perspectiva predominantemente dogmática, a la luz de las normas y principios que inspiran nuestro sistema civil y de las actuales soluciones y orientaciones que aportan otros sistemas legislativos.

El mismo aspira a servir de punto de partida para posteriores estudios en la materia, trazando algunas líneas que puedan obrar como antecedentes para una futura reforma legislativa.

PALABRAS CLAVES: autonomía privada, prescripción, caducidad, extinción.

\section{ABSTRACT}

This article has for objective to examine the scope of private autonomy in the regime of the statute of limitations and expiration in civil law, with an especial reference to the Uruguayan law.

The fundamental problem is that our Civil Code regulates insufficiently the statute of limitations, does not discipline the expiration of the rights and does not contain rules on the space that it is up to the private autonomy in the regime of these institutions.

The objectives of the work is to demonstrate that despite these shortcomings in the regulation is possible to recognize some room for the will of individuals, in line with modern legislation on comparative law, while highlighting the need for a profound reform of our Civil code.

The treatment of the theme will be done from a predominantly dogmatic perspective, in the light of the rules and principles that inspire our civil system and the current solutions and provide guidance to other legislative systems perspective.

It aims to serve as a starting point for further studies in this subject, drawing some lines that can act as a background for future legislative reform.

KEYWORDS: Private autonomy, prescription, expiration, termination.

\footnotetext{
* Profesor Agregado de Derecho Privado II y III en la Facultad deDerecho de la Universidad de la

República (Uruguay). Coordinador de la Facultad de Derecho en el Centro Universitario Regional del Litoral Norte (Uruguay).
} 


\section{INTRODUCCIÓN}

El acaecimiento de los fenómenos jurídicos se verifica en un determinado momento del tiempo. Su propio transcurso, junto a otros factores, constituye un hecho con importantes consecuencias en el mundo del Derecho.

Prescripción y caducidad, precisamente, son institutos en los que el tiempo opera como medida de su hecho constitutivo. Son vicisitudes extintivas de situaciones jurídicas activas, conexas con el transcurso del tiempo y determinadas por la inactividad lícita del sujeto (Ferrucci, 1966; Romano, 1964), pero que difieren en su configuración, fundamento y función. Adiferencia de la prescripción liberatoria, donde el efecto extintivo no acaece de pleno derecho, sino por la intermediación necesaria del ejercicio del poder atribuido al interesado en hacerla valer (Proto Pisani, 1991), la caducidad produce la extinción automática del derecho, siendo un hecho simple e instantáneo que se reduce a un solo elemento temporal, que fija la duración de la existencia del mismo (Bandrac, 1994; FauvarqueCosson \& François, 2008).

Entre los múltiples aspectos de relevancia que presenta el régimen jurídico de estas instituciones analizaremos los alcances de la actuación de la autonomía privada, principio estructural básico del sistema de relaciones sociales que más allá de todos los anuncios de debilitamiento y crisis en la realidad contemporánea sigue siendo un instrumento fundamental para la autorregulación de los intereses. Como ha dicho Scognamiglio (1990), en las relaciones sociales y económicas la posibilidad de disponer de los propios intereses representa un momento esencial de la libertad de la persona, que constituye un valor irrenunciable de la civilidad humana.

El tema reviste una enorme trascendencia jurídica, tanto teórica como práctica, que justifica plenamente un estudio tendiente a delimitar el espacio de libre actuación de la voluntad privada en la materia. Lo justifica también la propia actualidad de la temática, habida cuenta que las recientes legislaciones en el Derecho Comparado se orientan hacia el reconocimiento de un amplio cauce para la autonomía privada, superando así las soluciones tradicionales inspiradas en los Códigos decimonónicos.

El problema radica en que el Código Civil uruguayo de 1868 carece de una adecuada regulación de la temática objeto de análisis, dado el tratamiento insuficiente de la prescripción extintiva y la total ausencia de disciplina para la caducidad.

Los objetivos del presente trabajo son demostrar que a pesar de estas insuficiencias en la regulación se puede reconocer un cierto espacio para la autonomía privada, en armonía con las modernas tendencias en el Derecho Comparado, y señalar también la urgente y necesitada reforma de nuestro Código Civil en la materia. La aceleración del tiempo en el orden social en las últimas décadas, con una nueva dinámica en el tráfico económico y jurídico, ponen de manifiesto las notorias deficiencias del actual régimen de la prescripción extintiva y la necesidad de incorporar una orgánica disciplina de la caducidad.

\section{LAS MODERNAS TENDENCIAS EN LA REGULACIÓN DE LA PRESCRIPCIÓN EXTINTIVA.}

Señala Rivero Hernández (2002) que desde hace veinticinco años, y sobre todo en los diez últimos, ha aumentado el interés por la prescripción en el mundo jurídico occidental, tanto en el ámbito doctrinario como en el plano legislativo, con reformas significativas y nuevas normaciones de la institución, entre las que se destacan la de los Códigos Civiles holandés (1992), belga (1998), de Québec (1994) y del BGB (2001), con la entrada en vigencia el $1^{\circ} \mathrm{de}$ enero de 2002 de la Ley de Modernización del Derecho de Obligaciones (Gesetz zur modernisierung des Schuldrechts, del 26 de noviembre de 2001). Al mismo tiempo, en otros sistemas jurídicos, como el norteamericano, se ha incorporado por vía jurisprudencial una nueva interpretación de las normas sobre prescripción extintiva, creando nuevos principios en su aplicación, como la «delayed discovery doctrine», que retrasa el inicio de los plazos al momento en que el reclamante conoce o pudo conocer los hechos constitutivos de su pretensión. A ello se suma el hecho que el tema ha sido objeto de tratamiento en Congresos internacionales y de trabajos prelegislativos de corte transnacional, como los de la Comisión para el Derecho Contractual Europeo, todo lo cual para el doctrinario español es 
revelador de la inquietud y preocupación por la prescripción en ámbitos espaciales y jurídicos muy diversos, consecuencia de su importancia práctica, de la necesidad de una impostergable puesta al día en diversos aspectos, y sobre todo, de cierta coordinación de las legislaciones nacionales en un mundo cada día más interrelacionado.

En Alemania la reforma de 2001 ha significado una labor de recodificación del Derecho Privado con miras puestas en la unificación, teniendo en cuenta los Principios de Derecho Contractual Europeo, los Principios de Unidroit y la Convención de Naciones Unidas sobre Compraventa Internacional de Mercaderías de 1980 (Albiez Dohrmann, 2002; Cañizares Laso, 2003; Domínguez Luelmo, 2003; Infante Ruiz, 2002; Levano, 2004; Zimmermann, 2008). En materia de prescripción extintiva la reforma comportó una drástica reducción y simplificación de los plazos, incorporando un sistema mixto de cómputo, con un período ordinario y varios períodos máximos. En tal sentido el art. 195 dispone que el período ordinario de prescripción es de tres años, regla que se aplica a cualquier tipo de acción (legal, contractual o delictual), siendo su cómputo subjetivo (art. 199-I): comienza a contarse el plazo a la terminación del año en el cual ha nacido la pretensión y el acreedor adquiere conocimiento, 0 debiera adquirirlo sin culpa grave, de las circunstancias que sirven de fundamento a la pretensión y de la persona del deudor. A ello se agrega un sistema objetivo con plazos objetivos máximos de diez y treinta años: un período ordinario (199-4) y varios especiales (199-2 y 3 ), dispuestos en interés del deudor y a fin de eliminar definitivamente la incertidumbre frente al peligro de un plazo excesivamente largo si el acreedor tiene conocimiento de los hechos en forma muy tardía (Grothe, 2004; Levano, 2004). Sucede, como dice Cañizares Laso (2003), que un sistema unificado de prescripción sólo era posible mediante la unificación del comienzo de los plazos basados en el criterio subjetivo del conocimiento. Pero un sistema subjetivo único y genuino podría conducir a que las pretensiones nunca prescribieran si el titular de la misma no tiene conocimiento o posibilidad de conocimiento; por ello la seguridad jurídica y la función de la propia institución obligó a incorporar plazos máximos de corte objetivo (Albiez Dohrmann, 2002; Cañizares Laso, 2003).
Siguiendo esta tendencia la Ley 29/2002 de 30 de diciembre, Primera Ley del Código Civil de Cataluña, ha incorporado una renovación sustancial del derecho de la prescripción extintiva, que se explica según Ferrer Riba (2003) por la necesidad largamente sentida de reducir el plazo de prescripción, aprovechando el legislador la ocasión para replantear a fondo todos los núcleos temáticos del régimen de la institución, como ser inicio del cómputo, interrupción, suspensión y preclusión de plazos, efectos, alegación y renuncia. Para el doctrinario la incidencia del Derecho Comparado se manifiesta particularmente en el recorte generalizado y simplificación de los plazos, la fijación de un dies a quo subjetivo para el cómputo de los mismos (art. 121-23), la suspensión de éstos por razones familiares, sucesorias o de fuerza mayor, con el establecimiento de un plazo general de preclusión destinado a reequilibrar las incertidumbres que puedan suscitar los elementos subjetivos incorporados por las nuevas reglas de cómputo. Se establece un término común de diez años para la prescripción de cualquier clase de pretensión, con dos reglas específicas (art. 121-21 y 22).

El Código Civil de Bélgica, con la reforma de la Ley 39-1998, de 10 de junio, modifica el régimen de la prescripción reduciendo sus plazos, que quedan fijados para las acciones personales en diez años y para la reparación del daño extracontractual en cinco, contados desde que la persona lesionada ha tenido conocimiento del daño o su agravación y de la identidad del responsable, pero prescribiendo en todo caso cuando transcurran veinte años desde que se produjo el hecho que ha provocado el perjuicio (art. 2262-bis).

En el Derecho francés también se ha reformado el Código Civil en materia de prescripción mediante la Ley $N^{0}$ 561- 2008, de 17 de junio, fijando el plazo general de la prescripción en cinco años (art. 2224), reduciendo la multiplicidad de plazos existentes a unos pocos e incorporando un amplio margen de actuación de la autonomía privada, siguiendo fundamentalmente las líneas trazadas por la Ley de Modernización del Derecho alemán, los Principios de Derecho Europeo de los Contratos y los Principios de Unidroit. 
El Código Civil de Colombia, con la reforma de la Ley $N^{0} 791$, de 27 de diciembre de 2002, se orienta hacia la reducción de los plazos, con un sistema coherente de causas de interrupción y de suspensión, a fin de hacer operante el instituto ante las exigencias del mundo actual. En ese sentido se redujo el plazo de la prescripción extintiva ordinaria a diez años y el de la acción ejecutiva a cinco (art. 2536), la cual transcurridos los cinco años se convierte en ordinaria, durando otros cinco, sin perjuicio de otros plazos más breves de tres y de dos años previstos para las prescripciones de corta duración (arts. 2542 y 2543). Se ha querido que el plazo máximo durante el cual pueda prolongarse la incertidumbre sea de diez años, como lo demuestra el hecho que según el art. 2541 transcurridos diez años no se tomarán en cuenta las suspensiones previstas.

El Código Civil de Brasil de 2002 regula conjuntamente la prescripción extintiva y la decadencia de los derechos (arts. 189-211), estableciendo para la primera un plazo general de diez años (art. 205), con algunos pocos plazos más de uno, dos, tres y cuatro años para algunas pretensiones específicas (art. 206), con expresa prohibición de alterar los plazos legales por acuerdo de partes (art. 192) y la consagración de la prescriptibilidad de la excepción en el mismo plazo que la pretensión (art. 190).

El Código Civil y Comercial de Argentina de 2014 regula la prescripción extintiva y la caducidad en el Libro Sexto, disciplinando en forma conjunta la prescripción liberatoria y la usucapión, tanto en sus aspectos sustantivos como procesales, seguido luego de una regulación particular para la prescripción extintiva (arts. 2554-2564). A diferencia de otros sistemas, que optaron por separar la disciplina de ambas especies de prescripción, llevando la adquisitiva al Derecho de Cosas y la extintiva a la Parte General, el nuevo Código se orienta por el tratamiento en forma conjunta de los aspectos generales comunes. Se establece como principio general un término de cinco años para la prescripción extintiva (art. 2560), con plazos de diez, dos y un año para ciertas pretensiones (arts. 2561-2564), extremos que hemos examinado en anterior trabajo al cual nos remitimos (Rodríguez Russo, 2013).
En definitiva, existe una cierta tendencia hacia la reducción de los plazos y la simplificación del régimen de la institución, con un margen bastante amplio para la actuación de la autonomía privada, introduciendo como principio un sistema subjetivo de cómputo del plazo a partir del conocimiento o cognoscibilidad de la pretensión por el sujeto activo de la relación y de los datos para ejercerla, con ciertas dosificaciones. Es el sistema que han adoptado luego de sus respectivas reformas el BGB, el Código francés, el belga, el quebequés, el holandés y la Directiva europea 85-374 sobre responsabilidad por productos defectuosos. Es el que ha seguido también nuestra Ley de Relaciones de Consumo No 17.250 en su art. 38 .

\section{LOS SISTEMAS DE REGULACIÓN DE LA CADUCIDAD EN EL DERECHO COMPARADO.}

En el Derecho Comparado, como destaca Rivero Hernández (2002), se aprecian dos grandes concepciones en la regulación de la institución. Por un lado aquellos sistemas -como el alemán- que establecen un régimen uniforme, sin atender a la naturaleza de las relaciones sobre las cuales opera. Por el otro, aquellos -como el italiano- que distinguen entre relaciones disponibles e indisponibles, sometiéndolas a un diverso régimen en lo que respecta a renuncia, modificación y suspensión convencional de los plazos, forma de cómputo, apreciación de oficio por el juez.

Para el Derecho español, cuyo Código Civil, al igual que el nuestro, no contiene una orgánica disciplina del instituto, la doctrina estima útil atender a la naturaleza de la relación a fin de construir el régimen jurídico aplicable. En ese sentido dice el doctrinario citado (2002):

Aunque la cuestión no está clara en el actual régimen jurisprudencial de la institución, hay motivos razonables y bien fundados para hacer una cierta, incluso importante distinción entre los derechos y las relaciones indisponibles (derechos fundamentales, estado civil de la persona) y los sometidos a la disponibilidad de los interesados (retractos, acciones rescisorias y edilicias, de anulación contractual) a efectos del régimen jurídico de la caducidad, de sus plazos de ejercicio y otros extremos. (p 216). 
La tendencia en la materia es hacia una regulación diferenciada de la caducidad, de acuerdo al carácter disponible o indisponible de la relación jurídica. En ese sentido se pronuncian los Códigos italiano, portugués, catalán y boliviano.

Sin duda es preferible una disciplina de este tipo, pues no resulta adecuado someter a los derechos de naturaleza disponible al mismo régimen de los que no lo son, fundamentalmente en cuanto a estimación de oficio por el Juez, renuncia, modificación convencional de los plazos legales y suspensión de su curso por acuerdo de partes.

\section{EL ALCANCE DE LA AUTONOMÍA PRIVADA EN LA PRESCRIPCIÓN EXTINTIVA.}

La actuación de la autonomía privada, a la cual como dice Pietrobon (1971) le es connatural la idea de límites, está en directa conexión con el fundamento y función del instituto. La circunstancia que la prescripción esté dirigida a eliminar la incertidumbre derivada de la prolongada falta de ejercicio del derecho (Tedeschi, 1950, 1962), y por consiguiente al servicio de un interés general, no significa que toda su disciplina sea inderogable, ni que no pueda operar la voluntad privada, pues el propio Código admite la renuncia y el reconocimiento. De ahí que en algunos aspectos de su régimen puede actuar la voluntad de los particulares (Rodríguez Russo, 2007), lo que no significa por cierto que ella comprenda todos los extremos de la prescripción extintiva.

\section{El ámbito de la prescriptibilidad.}

De acuerdo a lo que dispone el art. 1193 de nuestro Código Civil la prescripción abarca en principio a los derechos de naturaleza patrimonial.

Son imprescriptibles los derechos de los que el sujeto no puede disponer absolutamente; su titular, como no puede disponer de ellos mediante actos de voluntad, tampoco puede disponer y perderlos absteniéndose de ejercitarlos (Irureta Goyena, 1945; Santoro Passarelli, 1964).

El ámbito de la prescripción extintiva se erige en un límite infranqueable a la autonomía privada, por estar fuera de la competencia de los particulares disponer negocialmente la prescriptibilidad de derechos que la ley declara imprescriptibles, o convertir en imprescriptibles derechos que por ley están sujetos a prescripción. Cualquier acuerdo de los particulares tendiente a convertir en imprescriptible un derecho para el que la ley establece la solución contraria, comportaría en sustancia una renuncia anticipada a la prescripción, expresamente prohibida por la ley (art. 1189).

La imprescriptibilidad está fuera de la autonomía de la voluntad de los particulares porque es un atributo de los derechos indisponibles que sólo la ley determina (Díez-Picazo \& Gullón, 1997). Lo corrobora la reforma alemana de 2001, que vino a admitir la autonomía privada en una amplia medida, pero no ha permitido los pactos sobre la prescripción de pretensiones imprescriptibles según la ley, ni la exclusión completa de la prescripción por vía contractual.

\section{Renuncia a la prescripción.}

Mediante la renuncia su titular se desprende del poder jurídico de invocarla (Gropallo, 1939; Pizarro \& Vallespinos, 1999; Pugliese, 1924), impidiendo así la eficacia de una sucesiva instancia de declaración de la prescripción (Giusiana, 1957). Su objeto en general es siempre un derecho o un poder; en la renuncia de la prescripción es el derecho a la liberación (Messineo, 1957).

El art. 1189 de nuestro Código permite que el beneficiado por la prescripción pueda renunciarla si está consumada, pero prohíbe la renuncia anticipada. Igual solución contiene el Código Civil de Perú (arts. 1990 y 1991).

\section{a) Renuncia anticipada a la prescripción extintiva.}

El fundamento de la prohibición está en el carácter de orden público que se atribuye a la prescripción. Si se permitiera semejante pacto se convertiría en una cláusula de estilo y las disposiciones de la ley, introducidas en interés general, llegarían a ser letra muerta (Abeliuk, 1993; Alas, De Buen \& Ramos, 1918; Baudry-Lacantinerie \& Tissier, 1908; Coviello, 1938; Ferrucci, 1966; Pizarro \& Vallespinos, 1999).

La ley ha temido que si la permitiera el acreedor se la impondría como una condición para la conclusión 
del contrato y el deudor la consentiría presionado por la necesidad, haciendo ilusoria la prescripción extintiva (Argañarás, 1966). Sería, pues, contrario al interés social y al fin de la institución.

\section{b) Renuncia a la prescripción en curso.}

La norma precedentemente citada impide la renuncia anticipada, planteándose la duda respecto a la prescripción en curso.

Para algunos autores, en la medida en que una prescripción en curso se encuentra ya parcialmente consumada, no habría dificultad en admitir que sobre ella también puedan las partes disponer lo que crean conveniente.

No es en rigor una renuncia anticipada prohibida por la norma, en tanto no se está abdicando de antemano a la facultad de hacer valer la prescripción, sino disponiendo del curso ya cumplido, surtiendo efectos hacia el pasado.

En ese sentido no habría obstáculos para la actuación de la autonomía privada, configurando ello un reconocimiento del derecho que interrumpe el curso de la prescripción, tal como lo ha previsto el art. 1234 del Código Civil.

\section{c) Renuncia a la prescripción ganada.}

El precepto legal permite la renuncia a la prescripción que se ha consumado porque ella comporta una ganancia que ha ingresado en el patrimonio del sujeto favorecido, convirtiéndose en un bien susceptible de negociación y renuncia (Abeliuk, 1993; Alas et al., 1918; Puig Brutau, 1996).

La facultad de renunciar a la prescripción es la razón por la cual el Juez no puede estimarla de oficio (art. 1191), quedando a la exclusiva voluntad del interesado invocarla o renunciar a hacerlo.

El fundamento de la renunciabilidad de la prescripción, dice Albaladejo (2004), se encuentra no solo en el principio de que cualquiera puede desprenderse de los beneficios o derechos que le pertenecen, sino en una razón de orden moral, que es la de admitir que quien considere injusto liberarse de tener que hacer lo que debe, pueda rechazar una liberación que a pesar de ser legal estime poco honrada. La ley permite que el interesado en alegar la prescripción pueda renunciar a esa facultad si lo desea, cediendo así a un escrúpulo de conciencia (Baudry-Lacantinerie \& Tissier, 1908; Carbonnier, 1952).

A través de la renuncia el sujeto beneficiado manifiesta la voluntad de no aprovecharse de la prescripción, subsistiendo en toda su plenitud la obligación con relación a la cual había corrido. Para el deudor no significa sino mantener en vida el derecho de crédito ajeno, puesto que hace dimisión del derecho a la liberación (Messineo, 1957).

Es un negocio jurídico unilateral de naturaleza abdicativa y de carácter no recepticio (Albaladejo, 2004; Ferrucci, 1966), cuya voluntad puede exteriorizarse a través de cualquier forma, pues la ley no exige ninguna en especial. Puede ser expresa o tácita, estableciendo la norma que hay renuncia tácita cuando media un hecho del deudor que implica un reconocimiento del derecho del acreedor, como si el deudor paga interés, pide plazo para cumplir y otros semejantes (constitución de garantías, pago parcial, etc.). Es suficiente, pues, un comportamiento cualquiera, incompatible con la voluntad de ampararse en la prescripción.

La renuncia hecha es irrevocable (Albaladejo, 2004; Pugliese, 1924) e implica la conciencia de la prescripción ocurrida, puesto que mal se podría renunciar a lo que no se conoce (Barbero, 1967; Pantaleón Prieto, 1995). La oportunidad para hacerlo es una vez que ha concluido el plazo respectivo y se encuentren presentes todos los requisitos para que el prescribiente pueda hacerla valer (art. 1189). Antes no, porque todavía no hay prescripción "consumada»; después de declarada la prescripción tampoco, pues tratándose de derechos creditorios se extingue la obligación civil y queda subsistente una obligación natural (art. 1442). Por otra parte, si la prescripción se declaró judicialmente es porque el prescribiente hizo uso de la facultad de invocarla; luego, no se concibe que pueda renunciar a un derecho potestativo que ya ha sido ejercitado. La prescripción extintiva en nuestro sistema no opera de pleno derecho, siendo necesario que el deudor la invoque y se declare judicialmente; hasta tanto ello no ocurra subsiste tal cual la obligación civil. 
El efecto de la renuncia es dejar intocada la obligación civil existente, provista de todos sus elementos (deuda y responsabilidad); por ende, habrá de extinguirse por cualquiera de los modos de extinción previstos por la ley (art. 1447).

No obstante, algunos autores (Argañarás, 1966; Gropallo, 1939; Pugliese, 1924) le atribuyen el efecto de rehabilitar o revivir el derecho extinguido por prescripción, conclusión que extraen del efecto automático asignado a la prescripción extintiva. Albaladejo (2004) acorde con su concepción que la prescripción no extingue nada, sino que el derecho se debilita dejándolo a la buena voluntad del obligado, expresa que la renuncia restablece la situación anterior tal cual era: ser exigible la obligación, pudiendo serle impuesto el derecho prescrito al obligado. Según Zenati \& Fournier (1996) ella no provoca la resurrección del derecho extinguido, sino el restablecimiento de su estructura normal, resultante del reconocimiento de su pertenencia al sujeto activo.

Coincidimos con Díez-Picazo \& Gullón (1997) en que se renuncia a la facultad de hacer valer la prescripción, nunca una hipotética resurrección del derecho subjetivo prescrito que lo volvería adquirir el que lo perdió por prescripción, pues sería un contrasentido que un derecho extinguido nace y se atribuye por la sola voluntad del sujeto pasivo, sin contar para nada con la voluntad del anterior titular. Tal resurgimiento sería además incompatible con el poder atribuido a los interesados (art. 1192 del Código Civil) de oponer la prescripción a pesar de la renuncia del deudor (Messineo, 1957).

\section{Reconocimiento del deudor.}

Es un acto unilateral por medio del cual se emite una declaración de voluntad destinada a producir efectos jurídicos, específicamente, a admitir la existencia de la obligación (Pizarro \& Vallespinos, 1999; Wayar, 2002).

Tal voluntad, que debe provenir del deudor o su representante, es no recepticia, pues como dice Albaladejo (2004), interrumpe el reconocimiento por sí mismo, sin necesidad de que se lo participe al acreedor, no solo porque no lo exige la ley, sino porque de ser recepticia su notificación lógicamente debería hacerse a la parte perjudicada, que en el caso es el propio reconocedor, siendo impensable que se pudiera pedir la notificación al acreedor favorecido por la interrupción de la prescripción.

Puntualiza Pugliese (1924) que la declaración de voluntad debe ser clara, precisa y específica, siendo insuficiente una cláusula genérica, como por ejemplo, si al asumir una nueva obligación el deudor expresa que se obliga sin perjuicio de otras deudas anteriores. Agrega que tampoco habrá reconocimiento cuando media una subordinación que destruye la sustancia de la declaración de voluntad, como sucedería si el deudor manifestare la voluntad de cumplir la obligación siempre que el acreedor pruebe la existencia de su derecho, pues es de la esencia del reconocimiento la exclusión de cualquier otra prueba del derecho.

No resulta tarea sencilla la determinación de su naturaleza jurídica. Así, para algunos doctrinarios (Baudry-Lacantinerie \& Tissier, 1908) si bien es un acto unilateral que interrumpe el curso de la prescripción, se trata de una simple confesión de la existencia del derecho; una declaración de conocimiento (declaración de ciencia), no un acto dispositivo (Messineo, 1978). Para otros autores es un acto no negocial (Ferrucci, 1966; Magazzù, 1960); un acto $o$ un negocio según las circunstancias, como lo sostiene Roselli (1988) para el reconocimiento del derecho de crédito en la caducidad.

Por nuestra parte consideramos que el reconocimiento es un negocio jurídico declarativo unilateral, cuyos efectos sobre la prescripción varían según tenga lugar durante el curso de la misma o luego de consumada.

En el primer caso es un negocio jurídico puramente declarativo que acredita la existencia de la obligación e interrumpe el curso de la prescripción; Pizarro \& Vallespinos (1999) lo ubican como negocio de fijación, dirigido a dar claridad y constancia a una situación anterior, sin requerir incertidumbre. Podrá resultar de un pago de intereses, una petición de prórroga, la constitución de garantías o cualquier otro comportamiento concluyente.

No se trata de una mera confesión pues ésta, según Cariota Ferrara (1956), es una declaración de verdad 
de hechos, en tanto el reconocimiento refiere a un derecho preexistente. El efecto de la confesión es meramente probatorio; el reconocimiento, además de acreditar la existencia de la obligación, interrumpe la prescripción, porque denota la voluntad de mantener viva la relación jurídica (Pizarro \& Vallespinos, 1999).

En cambio, en el segundo supuesto, cumplidas las condiciones de la prescripción extintiva, si el deudor pudiéndola invocarla no lo hace y reconoce el derecho del acreedor, se configura además una renuncia tácita a la prescripción ganada (negocio dispositivo de naturaleza abdicativa), conforme lo establece el art. 1189 del Código Civil.

\section{Modificación convencional de los plazos legales.}

El origen legal de los plazos es uno de los rasgos característicos y distintivos de la prescripción.

Como lo hemos señalado en nuestra obra (2010a), existen en la materia tres grandes sistemas legislativos: los que prohíben absolutamente alterar los plazos de prescripción; los que permiten reducirlos, pero no aumentarlos, y finalmente aquellos que, dentro de ciertos límites, permiten tanto abreviarlos como alargarlos. En efecto, en algunas legislaciones este tipo de estipulaciones está expresamente admitido, como es el caso del BGB (art. 225). En otros se encuentra prohibida, como sucede por ejemplo en los Códigos italiano, portugués, quebequés, holandés, suizo, cubano, que establecen la inderogabilidad de la disciplina de la prescripción. En los Principios de Derecho Contractual Europeo (art. 14:601), en el Código Civil francés luego de la reforma de 2008 (art. 2254) y en el Código Civil de Cataluña (art. 121-3), entre otros, se permite la modificación de los plazos por acuerdo de partes, especialmente la reducción o ampliación, aunque con determinados límites.

\section{a) Abreviación.}

En nuestro Código Civil, como en la mayoría de los códigos decimonónicos, no hay norma expresa sobre este tipo de estipulaciones. No obstante, la doctrina en general estima posible que los particulares prescribiente y prescrito- reduzcan la extensión de los plazos legales sobre la base de que ello no conspira contra la finalidad de la institución sino que, por el contrario, la refuerza, al eliminar más rápidamente el estado de incertidumbre (Carbonnier, 1952; García Amigo, 1978; Pantaleón Prieto, 1995). Coincidiría en ese sentido el interés general de liquidar prontamente las situaciones pendientes con el acuerdo de las partes.

Se dice que al no ser posible que la ley establezca el plazo de prescripción que convenga a las diversas situaciones particulares, se ha limitado a fijar un plazo máximo, dejando a los interesados el derecho de abreviarlo si lo estiman conveniente (BaudryLacantinerie \& Tissier, 1908).

Sin embargo, un importante sector de la doctrina niega validez a estos pactos (Argañarás, 1966; Bueres \& Mayo, 2000; Coviello, 1938; Gropallo, 1939; Pizarro \& Vallespinos, 1999; Pugliese, 1924). Se afirma que debe negarse a los particulares la potestad de acortar la duración de la prescripción, porque ella es materia de derecho preceptivo reservada a la ley, y por ende, inderogable. La ley debe determinar la duración máxima de la prescripción ordinaria, o la duración menor de las especiales, teniendo en cuenta las peculiaridades de los diversos grupos de derechos, atemperando de esa manera el interés del deudor, de liberarse en el menor tiempo posible, y el del acreedor, de conservar su derecho por el más largo tiempo (Pugliese, 1924).

Por nuestra parte consideramos que es posible la abreviación de los plazos legales mediante negocio jurídico, dentro de ciertas limitaciones; así, sería inválido un pacto que los acortase de tal manera que dejare al titular del derecho sin posibilidad real de ejercerlo, o que de otro modo lo dificultase de manera notoria (Cfme. Díez-Picazo \& Gullón, 1997; Gamarra, 1999). Este es el criterio seguido por el Código italiano para la caducidad convencional (art. 2965).

Destaca Rivero Hernández (2002) que en la concepción y funcionamiento de la prescripción hoy dominante se reconoce cierto margen a la autonomía en el ámbito de los derechos e intereses disponibles; tanto los autores como los Ordenamientos se muestran cada día más proclives a aceptar una limitada intervención de la voluntad privada en la modificación de los plazos, sobre todo para 
abreviarlos. Pero ese acortamiento no debe dejar indefensa o en situación de clara inferioridad a una de las partes.

No obstante, la doctrina advierte sobre los peligros y abusos que encierran este tipo de estipulaciones, fundamentalmente en los contratos por adhesión, en los que el predisponente puede abusar de su mayor poder negocial, extremo incontrovertible pero al que no ingresaremos dadas las limitantes de este trabajo, centrado en la actuación de la autonomía privada en el régimen del Código Civil, que disciplinó un modelo de contrato paritario, producto de la negociación de las partes.

\section{b) Ampliación.}

La mayoría de los autores se pronuncian en contra de este tipo de estipulación, dado el carácter de orden público de la institución y la prohibición de renunciar en forma anticipada (Abeliuk, 1993; Alas et al., 1918; Argañarás, 1966; Baudry-Lacantinerie \& Tissier, 1908; Berdaguer, 2014; Bueres \& Mayo, 2000; Carbonnier, 1952; Coviello, 1938; Enneccerus \& Nipperdey, 1981; García Amigo, 1978; Gropallo, 1939; Larenz, 1978; Pizarro \& Vallespinos, 1999; Pugliese, 1924; Santoro Passarelli, 1926).

Sin embargo, como advierten Díez-Picazo \& Gullón (1997), no es exacto que esta clase de pacto contenga una renuncia anticipada, pues lo que el precepto legal prohíbe es la imprescriptibilidad establecida convencionalmente, y de ello no se infiere que esté vedado un alargamiento de los plazos, salvo que por su extensión terminaren de hecho por convertir lo prescriptible en imprescriptible.

Entendemos que en nuestro sistema civil es posible acordar la extensión de los plazos legales dentro de ciertos límites temporales. En materia de derechos personales el plazo ordinario de la prescripción extintiva es de 20 años (art. 1216). Pero aquí, a diferencia de la caducidad, el momento final no es fijo, sino variable (Magazzù, 1960; Tedeschi, 1950) dado que pueden existir suspensiones e interrupciones en su curso. No obstante, las suspensiones que establece la Ley (art. 1243) tienen un límite: transcurridos 30 años no se tomarán en cuenta (arts. 1244 y 1569). El legislador, en aras a la certeza de las relaciones jurídicas, ha dispuesto que la situación en caso de suspensión del curso de la prescripción no pueda sobrepasar los 30 años, poniendo así un término final al estado de incertidumbre. Por lo tanto, dentro de este límite temporal es posible alargar los plazos legales, sin que medie renuncia anticipada a la prescripción o se vulnere el interés general.

En un plano estrictamente práctico parece razonable pretender alargar los plazos de las prescripciones cortas, pero no parece plausible la existencia de un interés que justifique la ampliación del plazo de la prescripción ordinaria, dado el extenso lapso que el Código establece como principio general.

El BGB a partir de la reforma admite el alargamiento de los plazos, también con un límite máximo de 30 años contados desde el punto de partida legal del plazo de prescripción (art. 202-II).

\section{Suspensión convencional del curso de la prescripción extintiva.}

La viabilidad de una suspensión dispuesta negocialmente da lugar a respuestas divergentes en la doctrina. Quienes la niegan se basan en el carácter de orden público de la prescripción, en que el Ordenamiento Jurídico regula la suspensión de la prescripción con normas imperativas inspiradas en motivos de interés general, que excluyen la libertad de los particulares (Pizarro \& Vallespinos, 1999; Pugliese, 1924).

De todos modos, dice Díez-Picazo (1964, citado en Albaladejo, 2004), hay que preguntarse si no cabría asignarle efecto interruptivo, desde que existe un claro reconocimiento del derecho en prescripción. La respuesta no puede ser sino negativa pues se daría el contrasentido que el negocio, que no produce el efecto realmente querido por las partes (suspensión), vendría a desplegar otro distinto y mayor (interrupción) que no ha sido pretendido.

A favor de la suspensión se pronuncian Alas et al. (1918) señalando que las partes pueden convertir en obligación a término la que era pura y simple, siempre que ello ocurría antes del comienzo de la prescripción, porque de lo contrario habría un reconocimiento por parte del deudor, que interrumpe su curso. 
A nuestro juicio eso no es suspensión, sino aplazamiento de la exigibilidad, pues estrictamente la suspensión convencional comporta la parálisis del curso de la prescripción comenzada.

Estimamos admisible la suspensión convencional del curso de la prescripción siempre que se determinen las circunstancias concretas y los extremos temporales en que opera, que en ningún caso podrían superar el límite señalado para los pactos que alargan la prescripción.

Si es viable un alargamiento de los plazos legales debe serlo también la suspensión, pues como anota muy bien Albaladejo (2004), «tanto alarga el que alarga, como el que deja de contar y luego recomienza, pero sin computar el tiempo en que no contó, pues así alejó el momento final». (p. 331). Por otra parte, no existe prohibición legal y el orden público lo que exige es que las normas sobre prescriptibilidad no queden al arbitrio de los particulares.

Habrá que tener cuenta, como dice Díez-Picazo, la causa del acuerdo y los efectos que pretenden las partes, siendo inadmisible una suspensión por tiempo indeterminado tendiente a excluir de forma permanente la verificación de la prescripción. En cambio, sería válido un convenio de ese tipo a fin de entablar determinadas negociaciones sin la premura por el vencimiento del término (Albaladejo, 2004), como lo ha dispuesto el BGB al establecer el efecto suspensivo de las negociaciones entre las partes respecto a las pretensiones en juego (art. 203).

\section{EL ALCANCE DE LAAUTONOMÍA PRIVADA EN LA CADUCIDAD.}

\section{Caducidad convencional.}

\subsection{Procedencia.}

A diferencia de la prescripción, en la caducidad se admite con carácter general para los derechos disponibles la posibilidad que el plazo tenga su origen en la voluntad privada (Cfme. Abeliuk, 1993; Argañarás, 1966; Barbero, 1967; Berdaguer, 2014; Caravita, 1942; De la Marniérre, 1933; Díez-Picazo \& Gullón, 1997; Ferrucci, 1966; García Amigo, 1979; Gómez Calle, 1995: Gropallo, 1939; Magazzù, 1960;
Messineo, 1979; Pugliese, 1924; Romano, 1964; Roselli, 1988; Santoro Passarelli, 1926; Tedeschi, 1962; 1950; Trabucchi, 1977).

Señala Roselli (1988) que en tanto cualquier derecho, salvo taxativas excepciones, nace sujeto a prescripción extintiva por el solo efecto de las normas generales al respecto, la caducidad no puede verificarse fuera de una especifica y expresa previsión legislativa o negocial.

En ese sentido, por ejemplo, los Códigos italiano (art. 2965), portugués (art. 330) y boliviano (art. 1516), permiten la estipulación voluntaria de la caducidad, con ciertas limitaciones. El Código Civil peruano, en cambio, establece la legalidad de los plazos, sin admitir pacto contrario (art. 2004).

En nuestro sistema, a pesar de que el Código Civil no la ha disciplinado, han sido previstas una serie de hipótesis que configuran típicos casos de caducidad, en las que se ha admitido expresamente la actuación de la autonomía privada. Esto sucede en materia de pacto comisorio (art. 1741), pacto de mejor comprador (art. 1743) y retroventa (art. 1754), donde el legislador ha dispuesto el término máximo de caducidad, dejando a criterio de los particulares, en aras a la seguridad y certeza de las relaciones jurídicas, autorregular sus intereses acordando la correspondiente extinción en un lapso menor. Con carácter general ello surge del inciso $2^{\circ}$ del art. 1229, en sede de prescripción, donde se contemplan los plazos acordados por las partes «en cualquier otra materia», expresión sin duda comprensiva de la caducidad.

La admisión de la voluntad privada en este ámbito genera un importante problema de delimitación con los pactos de abreviación de los términos de prescripción, que la doctrina es proclive a aceptar en líneas generales.

Por otra parte, en tanto la autonomía privada esta sujeta a limitaciones, la validez de este tipo de acuerdo no puede ser irrestricta, debiendo estar subordinada a la no vulneración de ciertas garantías mínimas. 


\subsection{Limitaciones}

Naturalmente, la caducidad negocial no es admisible en materia de derechos de naturaleza indisponibles, en la medida que se encuentran fuera de la competencia dispositiva de los particulares. Rivero Hernández (2002) expresa que esa es la caducidad prototípica, cuyo régimen resulta inderogable, dado el interés social y público afectado.

En ese ámbito el Código Civil italiano (art. 2968) consagra la inmodificabilidad de la disciplina legal de la decadencia. Sin embargo, como indica Roselli (1988), no es pacífico si un término de caducidad pueda operar aquí, pues la citada norma puede adoptarse a favor de la tesis positiva como argumento a contrario (si las partes no pueden modificar el término establecido por la ley, pueden en cambio establecer un término que la ley no ha previsto) y a favor de la tesis negativa como argumento analógico (si para los derechos indisponibles la caducidad es «establecida por la ley» y la disciplina es inmodificable, a fortiori no es posible crearla mediante negocio).

Pero aun para las relaciones y derechos disponibles la validez de estos pactos tiene como límite fundamental no tornar excesivamente difícil el ejercicio del derecho (Código Civil italiano, art. 2965; Código Civil boliviano, art. 1516).

Según Tedeschi (1962) y Magazzù (1960) la excesiva dificultad debe ser apreciada no solo en función de la brevedad del término, sino también de la situación del sujeto que ha de ejercer del derecho, teniendo en cuenta las concretas circunstancias, especialmente la naturaleza del acto a ser cumplido, de modo tal que un plazo de pocos días puede reputarse suficiente para la simple denuncia de un determinado hecho, pero insuficiente para promover una demanda.

Destaca Pugliese (1924) que el negocio jurídico en cuestión no puede ser utilizado in fraudem legis, que se verificaría si la sustitución de la prescripción por una caducidad convencional no va destinada a satisfacer el fin lícito de tutelar más enérgicamente el interés de la parte que la estipula en su propio favor, sino que es movido por el reprobable propósito de coartar excesivamente el ius agendi de la otra parte.

Con esa limitación, en materia disponible, las partes pueden crear ex novo una caducidad o modificar los plazos legales, ampliándolos o reduciéndolos (Magazzù, 1960).

\subsection{Caducidad convencional y pactos de abreviación de la prescripción extintiva.}

Si los plazos de la prescripción extintiva son inmodificables parecería una grave incoherencia admitir que en su lugar pueda acordarse una caducidad convencional, pues se afectaría gravemente la inderogabilidad de la disciplina de la prescripción (Ferrucci, 1966).

Sin embargo, como dice Gropallo (1939), tal contradicción es solo aparente, pues una cosa es estipular un término de decadencia y otra es abreviar el término de la prescripción, diversidad que deriva de la distinta función de ambas instituciones. Argumenta el doctrinario que no es lícito modificar los términos de la prescripción porque solo al legislador compete valorar y determinar cuanto tiempo conviene tolerar el estado de suspensión e incertidumbre derivado del no ejercicio de un derecho, pero no puede impedirse que las partes puedan obtener una rápida y pronta liquidación de la relación mediante la introducción de un termino de caducidad.

Según Pugliese (1924) si bien se consigue un resultado prácticamente igual, se lo obtiene por una vía diversa e indirecta, en la medida en que la prescripción no es modificada, sino sustituida por otro instituto dotado de una más rígida y enérgica eficacia; en suma, no se altera el medio legal, sino que se adopta otro medio.

En nuestro sistema, como ya se ha expresado, no existe norma que disponga la inderogabilidad de la disciplina de la prescripción extintiva, por lo cual, dentro de ciertos límites, son válidos los pactos tendientes a reducir los plazos, circunstancia que impone precisar los criterios para diferenciarlos de la caducidad convencional.

En opinión de Gropallo (1939) en la práctica no puede ser difícil discernir si se trata de una u otra 
estipulación, pues existen dos criterios fundamentales para identificar la caducidad convencional: 1) la brevedad del término (si las partes han dispuesto para el ejercicio de una acción un término de 15 años no puede decirse que han querido obtener una rápida liquidación de la relación, siendo por ende una abreviación del plazo de prescripción); 2) la costumbre entre las partes de concluir contratos similares con un breve término para el ejercicio de la acción (la frecuencia de tales relaciones permitirá reconocer e individualizar la función característica de la caducidad).

Por nuestra parte pensamos que el criterio básico para determinar si se trata de una caducidad convencional o de una reducción del plazo de prescripción es la intención de las partes. En el ámbito de las relaciones jurídicas disponibles rige el principio de autonomía privada, por lo que a lo primero que debe atenderse es a la voluntad de las partes; habrá que determinar, interpretación mediante, cuál ha sido la «intención común», si la extinción automática del derecho en un breve plazo o la disminución del término legal de prescripción. El criterio de la brevedad del término acordado servirá para resolver los casos dudosos en cuanto a la determinación de la intención de las partes y si esto no fuere posible por subsistir la ambigüedad se resolverá aplicando la regla de interpretación «favor debitoris» (art. 1304).

\section{Renuncia.}

\subsection{Renuncia anticipada.}

Para Pugliese (1924), dado el interés social involucrado, no es posible la renuncia anticipada a la caducidad. Pero un calificado sector de la doctrina la admite (Baudry-Lacantinerie \& Tissier, 1908; Magazzù, 1960; Pellizzi, 1957; Roselli, 1988; Tedeschi, 1962), sobre la base que las razones que obran para su prohibición en la prescripción extintiva no son aplicables a la caducidad en materia disponible. En tal sentido dice Magazzù (1960) que nada impide la renuncia al poder de oponer un hecho, siendo la prohibición de renunciar anticipadamente a la prescripción de corte excepcional, que se justifica por la específica razón de orden público, reconducible a una exigencia de tutela de un interés general que está en la base del instituto. Pero aquí el fundamento de la caducidad no es de orden público, por lo cual no es posible limitar la autonomía dispositiva del interesado, que será eficaz a condición que se verifique el hecho (inobservancia del término) al cual se conecta directamente el surgimiento del poder de oponerla. Renuncia que puede inferirse de hechos incompatibles con la voluntad de ampararse en ella y que difiere del reconocimiento impeditivo (Pellizzi, 1957; Tedeschi, 1962).

Consideramos que en la medida que los intereses involucrados no excedan la esfera de lo meramente individual podrá preventivamente el sujeto favorecido por la caducidad privarse del eventual poder de invocarla, pero no puede impedir que se consume si transcurre inútilmente el término sin que se realice el acto previsto, ni que pueda y deba ser estimada de oficio por el Tribunal en el proceso que se formule una pretensión basada en un derecho que ha caducado. A diferencia de la prescripción extintiva, que admite interrupciones provenientes de actos de quien se encuentra en situación jurídica pasiva y que solo opera cuando la haga valer judicialmente el mismo interesado, en la caducidad no está en el poder del sujeto pasivo impedir que se consume, ni que el derecho se extinga automáticamente por el solo transcurso del plazo.

\subsection{Renuncia a la caducidad en curso.}

Para Gropallo (1939) no es posible la renuncia a la caducidad en curso porque ello importaría interrupción, extremo incompatible con el concepto de caducidad.

Tal argumento puede ser objetado puesto que si la caducidad no es susceptible de ser interrumpida, mal puede haber interrupción por renunciar a la caducidad en curso.

El eventual favorecido podrá despojarse del poder de invocar la caducidad, pero no puede evitar que se verifique, máxime cuando el reconocimiento que pudiere aparejar es inidóneo para impedir la decadencia, a diferencia de la prescripción en curso, donde la renuncia comporta un reconocimiento interruptivo (Rodríguez Russo, 2008).

\subsection{Renuncia a la caducidad consumada.}

En los derechos disponibles una parte de la doctrina es proclive a admitir la renuncia a la caducidad (Albaladejo, 2004; Argañarás, 1966; Barbero, 1967; 
Calvo \& Ciatti, 2013; Gropallo, 1939; Pugliese, 1924; Roselli, 1988; Tedeschi, 1962; Santoro Passarelli, 1926) mientras otro sector se pronuncia en contra (Berdaguer, 2014; Gómez Calle, 1995; Irureta Goyena, 1945).

Dice Pugliese (1929) que si la caducidad ha cumplido su función, el efecto que provoca constituye un beneficio para la persona favorecida por la misma, por lo cual, al igual que la prescripción, puede renunciarse.

Entendemos que el sujeto favorecido puede renunciar a la caducidad y que al hacerlo abdica de su derecho a invocarla, pero no puede impedir que el derecho se extinga automáticamente, ni que a nivel procesal ello sea declarado de oficio por el Juez. Con la renuncia no se produce restablecimiento o resurgimiento alguno del derecho, lo cual, como advierten para la prescripción Díez-Picazo \& Gullón (1997), sería un evidente contrasentido: que un derecho extinguido pueda nacer y atribuirse por la sola voluntad del sujeto pasivo. Siendo rasgos tipificantes de la caducidad el obrar de pleno derecho, ser relevable de oficio e insusceptible de interrumpirse, una vez consumada la misma el derecho se habrá extinguido automáticamente. A partir de ese momento la renuncia de la persona beneficiada solo podrá tener por objeto el poder de hacerla valer, el derecho de invocar su propia liberación (Magazzù, 1960). No puede ser de otra manera, pues se renuncia a un derecho del propio renunciante, no a un derecho ajeno (el que caducó).

En el plano sustantivo la renuncia surtirá sus efectos y el renunciante, que abdicó del poder de hacer valer la caducidad, podrá actuar en términos tales de satisfacer el interés de la contraparte. Por ejemplo, caducada la acción redhibitoria, el vendedor que renunció al derecho de oponerla, ante requerimiento extrajudicial del comprador podrá proceder a la reducción del precio o a indemnizar el daño causado por el vicio oculto de la cosa vendida. Pero en un proceso judicial no podrá impedir que la caducidad de tal acción sea declarada de oficio por el Tribunal, desestimando la pretensión del comprador por haberse extinguido el derecho.

La diversidad existente entre caducidad y prescripción extintiva determina que en una y otra la renuncia del sujeto beneficiado tenga efectos diferentes respecto a la configuración del típico efecto de cada institución.

\section{Reconocimiento.}

Así como en la prescripción extintiva el reconocimiento puede tener lugar antes o después de operada, en la caducidad también hay que distinguir un reconocimiento impeditivo (durante el término de decadencia) y un reconocimiento que comporta renuncia (luego de consumada).

\subsection{Reconocimiento impeditivo de la caducidad.}

Mientras el curso de la prescripción extintiva puede ser interrumpido, la caducidad solamente puede ser impedida. Ahora bien, para excluir la caducidad no basta un acto indeterminado de ejercicio del derecho, sino que se exige el cumplimiento de un acto específico «previsto por la ley o el contrato» (arts. 2966 del CC italiano y 331 del CC portugués).

En esta institución se asigna relevancia extintiva a la falta de cumplimiento de un determinado acto dentro del término prefijado, de modo que cumplido tempestivamente el presupuesto de la misma viene a faltar definitivamente (impedimento). No existe aquí, como señala Tedeschi (1962), aquel reproducirse de la fattispecie que es característico de la interrupción de la prescripción, y por consiguiente, una vez impedida no puede surgir un nuevo término de caducidad.

Los sistemas que adoptan una concepción diferenciada establecen que impide la caducidad el reconocimiento del derecho por parte de la persona contra la cual se deba hacer valer el derecho, siempre que se trate de caducidad convencional o legal relativa a derechos disponibles. Este reconocimiento deberá consistir específicamente en un acto homólogo al previsto, de forma tal de tornar inútil el cumplimiento de éste; por ejemplo, en el caso que el acto previsto sea la denuncia de un vicio, se tratará del reconocimiento de la existencia del vicio (Magazzù, 1960; Pellizzi, 1957; Tedeschi, 1962).

La determinación de la naturaleza jurídica del mismo ha dado lugar a opiniones diversas en la doctrina italiana. Messineo (1978) considera que es una 
declaración de ciencia; Magazzù (1960) lo califica como acto jurídico no negocial de carácter unilateral, que puede y debe considerarse un equivalente del acto que debe cumplirse bajo caducidad, cuyo contenido puede adquirir un peculiar grado de especificidad. En cambio, para Roselli (1988) corresponde distinguir si lo sometido a caducidad es un derecho potestativo o un derecho de crédito: en el primer caso no puede operar el reconocimiento, puesto que tal derecho es actuable exclusivamente mediante la conducta de su titular, sin cooperación alguna del sujeto pasivo, que se encuentra, justamente, en una situación de sujeción o impotencia; en el segundo caso procede el reconocimiento, que tendrá naturaleza de acto o de negocio jurídico, según los casos.

Más allá de ello, la consagración legislativa del reconocimiento del derecho como causal de impedimento de la caducidad es una solución perfectamente coherente con la no invocación de oficio por el Juez que tanto el Código italiano (art. 2969), como el portugués (arts. 303 y 333) establecen para los casos de derechos no excluidos de la disponibilidad de los particulares.

En nuestro sistema, en el que no existe una regulación del instituto y en donde, además, las normas procesales (arts. 24 y 133 del Código General del Proceso) establecen que la caducidad es relevable de oficio por el Tribunal, sin distinguir si los derechos son disponibles o indisponles, la solución debe ser necesariamente distinta. La caducidad solo resultará impedida si dentro del plazo respectivo se ejerce el acto previsto por la ley o el negocio jurídico. Por consiguiente, ni el reconocimiento, la renuncia, o la falta de alegación por la persona contra quien se ejerce el derecho, obstarán a que la caducidad consumada sea relevada de oficio por el Juez.

\subsection{Reconocimiento del derecho luego de consumada la caducidad.}

Comporta renuncia a la caducidad el reconocimiento del derecho por parte del sujeto contra el cual deba hacerse valer, si se trata de derechos disponibles y tiene lugar una vez operada la misma (Gropallo, 1939; Magazzù, 1960; Roselli, 1988; Tedeschi, 1962).
Dicho reconocimiento, configurándose como acto de renuncia a la eficacia preclusiva de la caducidad, asume naturaleza negocial (Roselli, 1988).

La renuncia a la caducidad es admitida por los Códigos italiano (art. 2968, argumento a contrario) y portugués (art. 330), decisión legislativa coherente y armónica con la expresa consagración de la no estimación de oficio en materia de derechos disponibles, quedando al arbitrio de la parte interesada invocarla o renunciar a hacerlo.

Como señalamos precedentemente, en nuestro sistema la renuncia será admisible como negocio jurídico abdictativo a través del cual el sujeto se priva del derecho a invocar la liberación, pero no impedirá que la extinción del derecho opere automáticamente, ni que pueda y deba ser declarada de oficio por el Tribunal. En la prescripción extintiva es posible una renuncia que impide la verificación del efecto extintivo, pues no opera de pleno derecho, ni es estimable de oficio, siendo necesario que el interesado la haga valer mediante acción o excepción.

\section{Suspensión convencional de los plazos.}

Un importante sector de la doctrina admite los pactos de suspensión de los términos de caducidad para las relaciones jurídicas disponibles (Díez-Picazo \& Gullón, 1997; Gómez Calle, 1995; Lacruz Berdejo et al., 2005; Magazzù, 1960; Rivero Hernández, 2002; Tedeschi, 1942).

Ello es perfectamente justificable pues tratándose de derechos disponibles no resulta vulnerado el orden público, asumiendo positiva relevancia por ser compatibles los valores del cual es portador el negocio y los valores que expresa el ordenamiento, como señala Ferri (2001) al definir el Negocio Jurídico.

En Uruguay el Tribunal de Apelaciones en lo Civil de $6^{\circ}$ Turno (sentencia $\mathrm{N}^{0} 19$, del $1^{\circ}$ de octubre de 2003, Martínez Rosso (red.), Bossio, Hounie, caso 75, Anuario de Derecho Civil Uruguayo, Tomo 34) se ha pronunciado a favor de la suspensión convencional del plazo de caducidad de la acción de saneamiento (art. 1726 del Código Civil). En el caso las partes, en la audiencia de conciliación, habrían acordado la 
suspensión del plazo para entablar la acción «durante los procedimientos y por el tiempo que demore el peritaje». Señaló el Tribunal:

Si el vendedor puede ser relevado de su obligación de sanear los vicios ocultos mediante estipulación en contrario (art. $1719 \mathrm{CC}$ ), siempre que no los conociere 0 debiere conocer en razón de su oficio 0 arte, a «fortiori», en virtud del principio de quien puede lo más puede lo menos, debe ser válido y eficaz el pacto según el cual se suspende el plazo de caducidad para deducir la acción correspondiente. No se advierte razón de interés general o público que pudieran limitar el ejercicio en este ámbito de la autonomía privada. (p. 43).

Esta suspensión es admisible en la medida que se determinen las causas y circunstancias concretas, a fin de fijar con precisión la verificación del transcurso del plazo.

\section{CONCLUSIONES}

1. El Código Civil uruguayo aunque de manera imperfecta regula la prescripción extintiva, pero carece por completo de una específica disciplina de la caducidad.

2. A pesar de las insuficiencias en la regulación de estas dos instituciones es posible reconocer doctrinariamente un cierto margen de actuación de la autonomía privada en el régimen aplicable, conforme a los principios que rigen nuestro sistema civil.

3. Las modernas normaciones en la materia, como lo revelan un importante número de legislaciones comparadas, admiten un amplio campo en el que puede operar la voluntad de los particulares, fijando además plazos de prescripción relativamente breves y estableciendo una orgánica disciplina para la caducidad.

4. La aceleración del tiempo en el orden social en las últimas décadas, con una nueva dinámica en el tráfico económico y jurídico, ha puesto de manifiesto las deficiencias de la regulación de la prescripción extintiva en nuestro actual Código Civil y la necesidad de una profunda reforma legislativa.
Como lo ha señalado Patti (2010), los Códigos Civiles fueron concebidos en su momento para disciplinar un mundo distinto del de hoy; el mundo de ayer era «el mundo de la seguridad», caracterizado por un ordenado desarrollo de las relaciones sociales y de la previsibilidad de los distintos acontecimientos en las distintas fases de la vida. En ese contexto de regularidad y certeza, y de lento desarrollo de las relaciones sociales, se justificaban los extensos plazos ordinarios de prescripción, que en esa instancia representaban una buena parte de la vida de la persona humana y que hoy se revelan completamente inadecuados.

5. La reforma de nuestro Código Civil debería ir dirigida a una abreviación de los términos de prescripción, trazando con precisión los límites operativos de la autonomía privada, con un plazo general de cinco años como máximo, sin perjuicio de algunos especiales que contemplen las particularidades de ciertas relaciones jurídicas. $Y$ dejar a la iniciativa privada la abreviación o extensión de los mismos dentro de ciertos límites razonables, a través de la fijación de topes mínimos y máximos, como lo ha hecho el Código francés con la reforma de 2008, que no permite acortar a más de un año, ni extender a más de diez (art. 2254). La reducción de la extensión de los plazos deberá ir acompañada de una simplificación y disminución del número de términos especiales, que hoy existen en demasía en nuestro Código, con la completa supresión de las prescripciones "presuntivas», que en ese contexto carecerían de toda razón de ser (Rodríguez Russo, 2010a, 2014).

6. La instancia de reforma debería ser propicia además para introducir a nuestro sistema una disciplina unitaria y diferenciada de la caducidad, según el carácter disponible o indisponible de la relación jurídica, con una precisa delimitación del espacio que le cabe a la autonomía privada y de las normas de la prescripción extintiva que resultarían aplicables, acorde a un elemental principio de técnica legislativa.

\section{REFERENCIAS BIBLIOGRÁFICAS}

Abeliuk, R. (1993). Las obligaciones, 2, Santiago: Editorial Jurídica de Chile. 
Alas, L., De Buen, D. \& Ramos, E. (1918). La Prescripción Extintiva, Madrid: Centro de Estudios Históricos.

Albaladejo García, M. (2004). La Prescripción Extintiva, Madrid: Fundación Beneficentia et Peritia luris.

Albiez Dohrmann, K. J. (2003). La Modernización del Derecho de Obligaciones en Alemania: un paso hacia la europeización del Derecho Privado, Revista de Derecho Privado, 3, 187-206.

Argañarás, M. (1966). La Prescripción Extintiva, Buenos Aires: Tea.

Bandrac, M. (1994). Les téndances recentes de la prescription extinctive en Droit français, Revue Internationale de Droit Comparé, 2, 359-377.

Barbero, D. (1967). Sistema de Derecho Privado, 1, Buenos Aires: Ejea.

Baudry-Lacantinerie, G. \& Tissier, A. (1908). Tratatto teorico-pratico di Diritto Civile. Della Prescrizione, Milano: Francesco Vallardi.

Berdaguer, J. (2014). Fundamentos del Derecho Civil, 4, Montevideo: Fundación de Cultura Universitaria. Bueres, A. \& Mayo, J. (2000). Aspectos generales de la prescripción liberatoria, Revista de Derecho Privado y Comunitario, 22, 335-351.

Calvo, R. \& Ciatti, A. (2013). Diritto Privato, Bologna: Zanichelli.

Candian, A. (1961). Instituciones de Derecho Privado, México: Uteha.

Cañizares Laso, A.(2003). La prescripción en el BGB después de la reforma del Derecho de las Obligaciones, Estudios Jurídicos en Homenaje al Profesor Luis Díez-Picazo, 1, 409-431.

Caponi, R. (1996). Gli impedimenti all' esercizio dei diritti nella disciplina della prescrizione, Rivista di Diritto Civile, 6, pp. 721-761.

Caravita di Toritto, B. (1942). La prescrizione e la decadenza, Giurisprudenza Italiana, 94, 306-312.

Carbonnier, J. (1952). Notes sur la prescription extinctive, Revue Trimestrielle de Droit Civil, 171-181. Cariota Ferrara L. (1956). El Negocio Jurídico, Madrid: Aguilar.

Carnelutti, F. (1933). Appunti sulla prescrizione, Rivista di Diritto Proccessuale Civile, 10, 32-49.

- (1955). Teoría General del Derecho, Madrid: Revista de Derecho Privado.

Coviello, N. (1938). Doctrina General del Derecho Civil, México: Uteha.

De Cossío, A. (1979). Instituciones de Derecho Civil, Madrid: Alianza Editorial.
De la Marniérre, S. (1933). La déchéance como mode de extinction d'un droit. Essai de terminologie juridique, Revue Trimestrielle de Droit Civil, 32, 1037 1113.

Díez-Picazo, L. \& Gullón Ballesteros, A. (1997). Sistema de Derecho Civil, 1, Madrid: Tecnos, $9^{a}$ edición.

Domínguez Luelmo, A. (2003). Alteración convencional de los plazos de prescripción extintiva en Derecho de Obligaciones, Estudios Jurídicos en Homenaje al Profesor Luis Díez Picazo, 1, 473-493. Domínguez Luelmo, A. \& Álvarez Álvarez, H. (2009). La prescripción en los PECL y en el DCFR, InDret, 3, 1-26.

Enneccerus, L. \& Nipperdey, H. (1981). Derecho Civil. Parte General, 1, Vol. 2, Barcelona: Bosch.

Fauvarque Cosson, B. \& François, J. (2008). Commentaire de la loi du 17 juin 2008 portant réforme de la prescription en matière civile, Recueil Dalloz, 36, 2512-2522.

Ferrer Riba, J. (2003). Los efectos de la prescripción en el Derecho Civil de Cataluña, InDret, 2, 1-10. Ferri, G. B., (2001). II Negozio Giuridico, Padova: Cedam. Ferrucci, R. (1966). Prescrizione Estintiva (Diritto Civile), Novissimo Digesto Italiano, 13, 640-653.

Gamarra, J. (1999). Tratado de Derecho Civil Uruguayo, 17, Montevideo: Fundación de Cultura Universitaria.

García Amigo, M. (1979). Instituciones de Derecho Civil. Parte General, Madrid: Edersa.

García Vicente, J. R. (2003). Modificación convencional de los plazos de prescripción. Comunicación en

XII Jornades de Dret Catalá a Tossa. Disponible en: http://civil.udg.edu/tossa/2002/textos/com/3/jgv.htm. Giusiana, E. (1957). Appuntti sulla prescrizione, Rivista di Diritto Civile, 1, 424-452.

Gómez Calle, E. (1995). Caducidad, Enciclopedia Jurídica Básica, 1, 857-859.

Gropallo, E. (1939). Prescrizione Civile, Nuovo Digesto Italiano, 17, 220-242.

Grothe, H. (2004). La Reforma del Derecho alemán de las Obligaciones, Revista de Derecho Comparado, 8, 7-30.

Infante Ruiz, F. (2002). Apuntes sobre la reforma alemana del Derecho de Obligaciones: la necesitada modernización del Derecho de Obligaciones y la Gran Solución, Revista de Derecho Patrimonial, 8, 153171. 
Irureta Goyena (h), J. (1945). Diferencias entre prescripción y caducidad, Revista de Derecho Público y Privado, 89, 258-261.

Lacruz Berdejo, J. L., Sancho Rebullida, F. A., Luna Serrano, A., Delgado Echeverría, J., Rivero Hernández, F. \& Rams Albesa, J. (2005). Elementos de Derecho Civil. I. Parte General, 3, Madrid: Dykinson.

Larenz, K. (1978). Derecho Civil. Parte General, Jaén: Edersa.

Levano, Y. (2004). La Prescription Extinctive en Droit Alemand aprés la Réforme du Droit des Obligations, Revue Internationale de Droit Comparé, 4, 947-958. Magazzù, A. (1960). Decadenza (Diritto Civile), Novissimo Digesto Italiano, 5, 231-240.

Messineo, F. (1957). Variazioni sul concetto di rinunzia alla prescrizione, Rivista Trimestrale di Diritto e Procedura Civile, I, 505-518.

- (1979). Manual de Derecho Civil y Comercial, 2, Buenos Aires: Ejea.

Pantaleón Prieto, F. (1995). Prescripción, Enciclopedia Jurídica Básica, 3, 5008-5013.

Patti, S. (2010). Certezza e giustizia nel Diritto della prescrizione in Europa, Rivista Trimestrale di Diritto e Procedura Civile, 64, 1, 21-36.

Pellizzi, G. (1957). In margine al problema della decadenza, Giurisprudenza Italiana, 109, 37-43.

Pietrobon, V. (1971). El error en la doctrina del Negocio Jurídico, Madrid: Editorial Revista de Derecho Privado.

Pizarro, R. \& Vallespinos, C. (1999). Instituciones de Derecho Privado, 3, Buenos Aires: Hammurabi.

Proto Pisani, A. (1991). Appunti sulla tutela c.d.costitutiva, Rivista di Diritto Processuale, 46, 2, 61-100.

Pugliese, G. (1924). La Prescrizione nel Diritto Civile. II. La Prescrizione Estintiva, Torino: Utet.

Puig Brutau, J.(1996). Caducidad, Prescripción Extintiva y Usucapión, Barcelona: Bosch, $3^{\mathrm{a}}$ edición. Rivero Hernández, F. (2000). La prescripción y la caducidad. Perspectivas legislativas, Ponencia en XI Jornades de Dret catalá a Tossa, Disponible en: http:/ /civil.udg.edu/tossa/2000/Textos/p/3/rivero.htm.

- (2002), La suspensión de la prescripción en el Código Civil español. Estudio crítico de la legalidad vigente, Madrid: Dykinson.

Rodríguez Russo, J. (2007). Autonomía privada en materia de prescripción extintiva y caducidad en el sistema del Código Civil uruguayo. Primera Parte, Anuario de Derecho Civil Uruguayo, 37, 675-684.
- (2008). Autonomía privada en materia de prescripción extintiva y caducidad en el sistema del Código Civil uruguayo. Segunda Parte, Anuario de Derecho Civil Uruguayo, 38, 789-798.

- (2010a). Prescripción Extintiva y Caducidad en el Derecho Civil, Montevideo: Fundación de Cultura Universitaria.

- (2010b). La prescripción extintiva en el pago de lo indebido, Anuario de Derecho Civil Uruguayo, 40, 969-978.

- (2012). Caducidad de la hipoteca, Anuario de Derecho Civil Uruguayo, 42, 569-584.

- (2013). La regulación de la prescripción extintiva y la caducidad en el Anteproyecto de Código Civil y Comercial de la República Argentina de 2012, Revista de la Facultad de Derecho, 33, 113-142.

- (2014). Codice Civile e dispersione legislativa. Alcune considerazioni intorno alla situazione nel diritto civile uruguaiano, Rassegna di Diritto Civile, 3, 850889.

Romano, A. (1964). Note in tema di decadenza, Rivista Trimestrale di Diritto e Procedura Civile, 1, 171- 238.

Roselli, F. (1988). Decadenza. I) Diritto Civile, Enciclopedia Giuridica Treccani, 10, 1-7.

Santoro Passarelli, F. (1926). Prescrizione e decadenza, Rivista di Diritto Civile, 1, 556-579.

- (1964). Doctrinas Generales del Derecho Civil, Madrid: Editorial Revista de Derecho Privado.

Scognamiglio, R. (1990). Negozio Giuridico. I) Profili Generali, Enciclopedia Giuridica Treccani, 20, 1-9. Tedeschi, V. (1942). Prescrizione estintiva e decadenza, Rivista Trimestrale di Diritto e Procedura Civile, 1, 56-58.

- (1950). Ancora sulla distinzione tra prescrizione estintiva e decadenza, II Foro Civile, 1, 242-248.

- (1962). Decadenza, Enciclopedia del Diritto, 11, 770-792.

Tescaro, M. (2012). L'incertezza della prescrizione: l'esempio del danno da mancato recepimento di direttive comunitarie nella legge di stabilità 2012, Rivista di Diritto Privato, 2, 195-206.

Trabucchi, A. (1977). Istituzioni di Diritto Civile, Padova: Cedam, $22^{\mathrm{a}}$ edizione.

Wayar, E. (2002). Derecho Civil. Obligaciones, 2 Buenos Aires: Depalma.

Zenati, F. \& Fournier, S. (1996). Essai d'une théorie unitaire de la prescription, Revue Trimestrielle de Droit Civil, 2, 339-353.

Zimmermann, R. (2008). El Nuevo Derecho alemán de Obligaciones, Barcelona: Bosch. 